\title{
Estimation of the hundred year return level of the significant wave height for the French Guiana coast
}

\author{
Robert Osinski ${ }^{\text {*}}$, , Alice Dalphinet ${ }^{2}$, Lotfi Aouf ${ }^{2}$, Philippe Palany ${ }^{l}$ \\ ${ }^{1}$ Météo France, Direction Interrégionale Antilles-Guyane - Fort-de-France - Martinique - France \\ (Route du Général Brosset - Morne Desaix - BP 645 - 97262 Fort-de-France Cedex) \\ ${ }^{2}$ Météo France, Direction des Opérations pour la Prévision - Département prévision marine et océanographique - Toulouse - Haute- \\ Garonne - France \\ (42, Av. G. Coriolis, 31057 Toulouse Cedex 1) \\ *Corresponding author: robert.osinski@gmail.com
}

The coast between the Amazon River mouth in Brazil and the Orinoco River mouth in Venezuela is one of the muddiest in the world. Large amounts of sediments from the Amazon River are transported along-shore by the North Brazilian current (NBC) and influence the formation of mud banks and wave breaking along the coast (Gratiot et al., 2007). During November and March, this coast is affected by strong wave events, the socalled northerly swells, which can provoke inundations and damages. Van Ledden et al. (2008) show an example of such an event affecting the Guyana coast. In this study, the focus is on French Guiana. The aim of this study is an estimation of return levels of different return periods of significant wave heights, here demonstrated for 100 years. Such an estimation is for example important for the structural design of coastal protection installations. The impact of ocean/coastal currents on the wave height is demonstrated in a case study. An event sample as large as possible is created as input for the extreme value theory (Coles, 2001), because of the low probability of occurrence of the high impact events.

Météo France as the national weather service is responsible for the operational forecasts of the sea state and the official warnings for the study region. For the warning process, the knowledge about the return period of a predicted extreme event can be used as additional information to quantify its rarity. The operational model chain for wave forecasts is applied to produce high resolution hindcasts of severe northerly swell events affecting the French Guiana coast. This includes a new regional model for French Guiana. As it became operational recently, the period of archived forecasts is not long

Submitted on: 2/April/2018

Approved on: 14/December/2018

http://dx.doi.org/10.1590/S1679-87592018017906604 enough for the statistics. Operational forecasts/analysis are also inhomogeneous due to the constant improvements of the involved models. Wave data ( $1^{\circ}$ resolution) and wind data $\left(\sim 0.7^{\circ}\right)$ from the ERA-Interim reanalysis (Dee et al., 2011) are available every six hours from 1979 onwards. This homogeneous dataset is used to identify event periods and to drive the model chain. A new reanalysis called ERA5 is in production and hourly wave/ wind data at $0.36^{\circ} / 0.28^{\circ}$ between 2010 and 2016 were available at the time of this study. Both wave reanalysis are too coarse at the coast to represent the wave properties sufficiently in shallow water for the purpose of this study. 2013 ERA-Interim and ERA5 data were tested for model calibration and for sensitivity studies of the influence of ocean currents on the wave height. Indeed, the impact of ocean/coastal currents and mud banks on the waves is not taken into account in the Météo-France operational model chain yet. This leads to uncertainties in forecasts as well as in the hindcasts, which have to be quantified.

The global WAM wave model (WAMDI Group, 1988 ) with a resolution of $0.5^{\circ}$ used in operational service at Météo France called MFWAM is applied in this study. The MFWAM model is based on the IFS-ECWAM code (IFS-38R2) (ECMWF, 2013) with two major changes in the source terms related to dissipation by wave breaking and a swell damping by air friction as developed in Ardhuin et al. (2010), called ST4 physics. Hindcast events are produced by driving the global model with 10 $\mathrm{m}$ winds and sea ice cover fraction from ERA-Interim reanalysis over a period of 38 years (1979-2016). A configuration of the WAVEWATCH III ${ }^{\circledR} 4.18$ model (WWIII) (Tolman et al., 1991, 2014) for French Guiana (Michaud et al., 2018) is nested into MFWAM. It has been developed by the Service Hydrographique et Océanographique de la Marine (SHOM) in collaboration with MétéoFrance in the framework of the Homonim project. This 
configuration runs on an irregular grid with maximum resolution of about $200 \mathrm{~m}$ at the coast. The model is driven by lateral boundary conditions from the global model and the ERA-Interim winds. As the swell is the predominant part of the wave energy in this region, a potential underestimation of the wind sea is assumed to impact only slightly the total wave height. In the operational chain, an intermediate MFWAM configuration at $0.1^{\circ}$ is nested into the global model, but not used in this study. Indeed, a test with such a regional MFWAM showed only a negligible impact, probably because of the relatively low resolution of the driving wind data.

Reanalysis data are used in this study to be able to produce a homogeneous set of events over a 38 years period. The model chain is calibrated for the application with operational atmospheric forcing data. As the ERAInterim and ERA5 reanalysis have a coarser resolution than the wind data used for the operational setup, the wind distributions can differ in regard to the operational forcing. For this reason, several parameters have been adapted for calibration and the setup has been validated against observations. Along track altimeter data for 2013 from the Ifremer CERSAT data base (available from ftp://ftp.ifremer.fr/ifremer/cersat/products/swath/altimeters/waves/data/) has been used for this purpose. This includes the instruments JASON1, JASON2, CRYOSAT and SARAL. The measured CERSAT significant wave height data, which are subject to different corrections described by Queffeulou (2004), are applied in this study. Measurements along track that are falling into predefined $0.5^{\circ} \times 0.5^{\circ}$ grid cells are averaged and collocated to the nearest model grid point with a maximum time delay of 1h30. Data below $0.5 \mathrm{~m}$ and above $13 \mathrm{~m}$ are excluded.

Objective scores calculated between the collocated observation-model pairs are used for model validation. The bias and scatter index (Zambresky, 1989) in the North Atlantic ocean, where distant swells are generated, are shown in Figure 1. Using the same wave model parameters as in the operational setup leads to a negative bias of about $21 \mathrm{~cm}$ (Figure 1a) nearly all over the Atlantic, including the northern coast of South America around French Guiana. As MFWAM is used here to provide boundary conditions for WWIII, model parameters have been adapted to reduce the bias in the region where the open boundaries of WWIII are located.
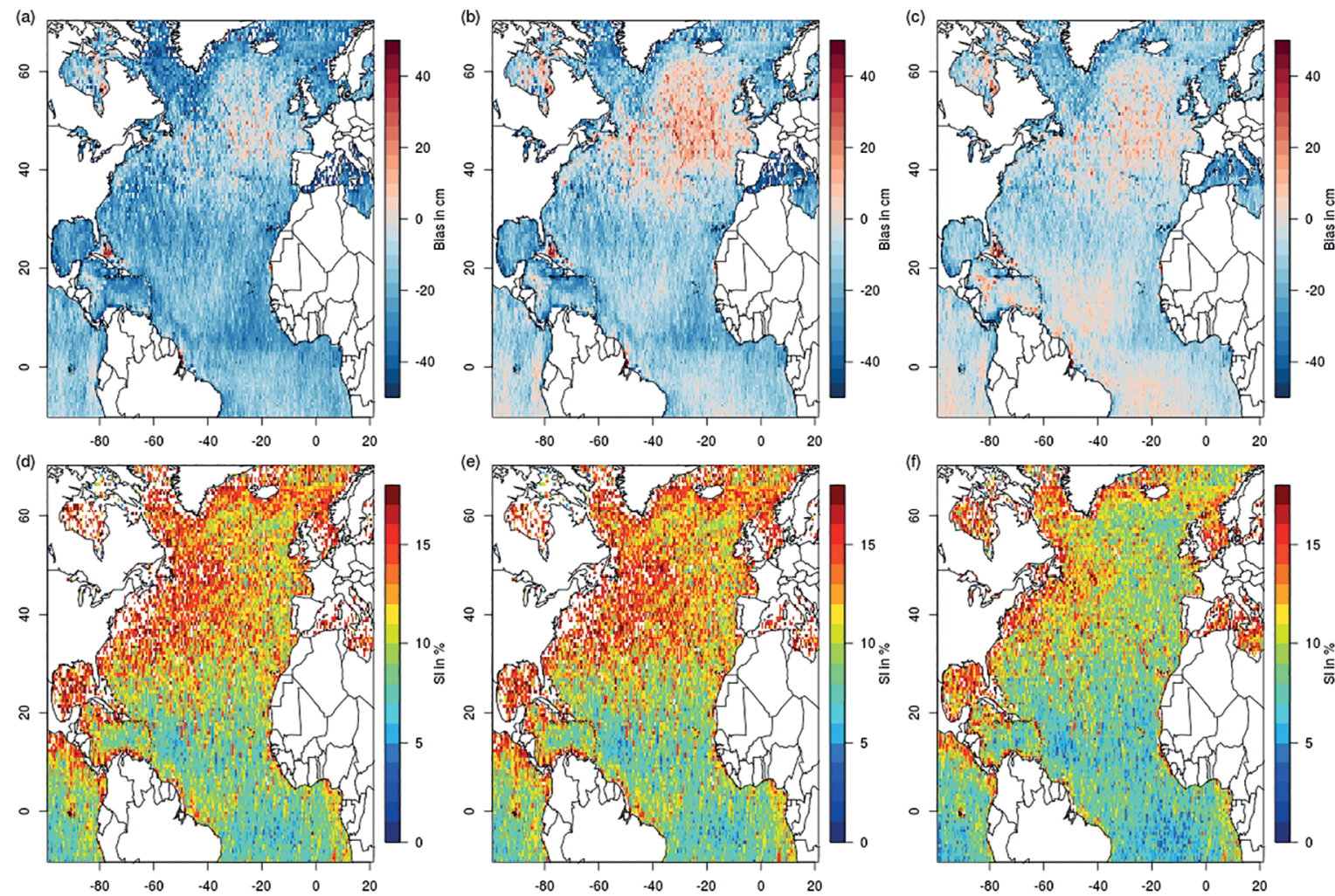

Figure 1. Bias (a-c) $[\mathrm{cm}]$ and scatter index (d-f) [\%] of MFWAM against altimeter data for 2013 in the North Atlantic under various model configurations: before (a and d) and after calibration (b,c,e,f), with ERA-Interim 6-hourly (a,b,d,e) and ERA5 hourly (c and f) $10 \mathrm{~m}$ wind forcings. 
Gorman and Oliver (2018) proposed a methodology to determine an optimal set of such parameters and showed an example of WWIII driven by ERA-Interim. The parameters from this study were used as an orientation. As the special focus is on French Guiana, they were tuned specifically for this region. Compared to the operational setup, some parameters related to the wind impact and wave dissipation were changed. The configuration used for these source terms corresponds to the development of Ardhuin et al. (2010). The parameter of dissipation SDSC2 has been adjusted from $-2.810^{-5}$ to $-2.010^{-5}$. The sheltering coefficient for short waves TAUWSHELTER used in the wind impact source term has been reduced from 0.6 to 0.4 . The tail factor, which determines the shape of the energy spectrum at high frequencies, has also been reduced from 9.9 to 4 . Figures $1 \mathrm{~b}$ and $1 \mathrm{e}$ show the improvement of the scores due to these modifications. Using ERA5 data, and the same calibration, the scores get further improved (Figures 1c and 1f). Table 1 provides additional verification scores over a smaller region, we are calling “Antilles-Guyane" $\left(75^{\circ} 00^{\prime} \mathrm{W}\right.$ to $45^{\circ} 00^{\prime} \mathrm{W}$ and $5^{\circ} 00^{\prime} S$ to $28^{\circ} 00^{\prime} \mathrm{N}$ ), covering a broad area from the central and eastern Caribbean down to the Amazon river mouth, and including the WWIII open boundaries. Using thousand bootstrap replications, the score differences were tested for significance. In the operational configuration, the same parameter set is used for both WWIII and MFWAM. For this reason, the aforementioned changes in parameter values were also applied to WWIII. Due to a lack of observational data (wave buoys) and a lack of resources to conduct long simulations with WWIII for comparison with altimeter data, whose quality near the coast is limited, WWIII has not been validated again.
A selection of events for the application for the extreme value statistics is based on the 38 years of ERAInterim wave data. The mean residual lifeplot (MRL) has been used for estimating a threshold value for the Peaks-over-threshold theory (POT) (Coles, 2001). It was applied on the entire set of 6-hourly data of the wave reanalysis ignoring dependencies in a first step (Fawcett and Walshaw, 2007). This was done for the closest ERA-Interim ECWAM grid point in front of Cayenne (location of Cayenne shown in Figure 5), as this is one of the focus regions. Several thresholds were also tested to fit a General Pareto Distribution (GPD) to identify at which threshold the fit parameters become more or less constant. To be able to make an estimation over all grid points, the percentile of the estimated threshold was determined. The same percentile was tested aleatory for several grid points over the entire WWIII domain. This threshold, which is the $99^{\text {th }}$ percentile of all ERA-Interim 6-hourly significant wave height data, was then used for a declustering using a run parameter (Coles, 2001) of $48 \mathrm{~h}$. This means that two exceedances of the threshold are assumed to belong to the same event, if the temporal distance is less than 48 hours. It can happen that a large cluster lasting several days is detected, because the gaps between threshold exceedances last less than 48 hours. Within such clusters, the duration from the beginning of one subcluster until the end of the next one is considered. If it is shorter than 48 hours then the following subclusters are assigned to the same event. This is done iteratively taking also the next subclusters into account. The groups that exceed 48 hours are separated, so that most of the long lasting clusters are splitted into several. Only the maximum value of each event is extracted to fit a GPD. Although this procedure is

Table 1. Verification scores of the significant wave height of 3 hourly data for 2013 for MFWAM $0.5^{\circ}$ without currents for the Antilles-Guyane region $75^{\circ} 00^{\prime} \mathrm{W}$ to $45^{\circ} 00^{\prime} \mathrm{W}$ and $5^{\circ} 00^{\prime} \mathrm{S}$ to $28^{\circ} 00^{\prime} \mathrm{N}$ (entire region of Fig. 1) against altimeter data.

\begin{tabular}{lccc}
\hline & $\begin{array}{c}\text { MFWAM operational with } \\
\text { ERA-Interim }\end{array}$ & $\begin{array}{c}\text { MFWAM calibrated with ERA- } \\
\text { Interim }\end{array}$ & $\begin{array}{c}\text { MFWAM calibrated with } \\
\text { ERA5 }\end{array}$ \\
\hline Bias $[\mathrm{cm}]$ & $-20.7(-19.5)$ & $-14.2(-10.7)$ & $-5.2(-7.7)$ \\
rmse $[\mathrm{cm}]$ & $30.7(40.0)$ & $26.5(37.0)$ & $20.7(29.8)$ \\
Scatter index [\%] & $11.8(15.2)$ & $11.6(15.4)$ & $10.5(12.5)$ \\
Correlation & $0.93(0.96)$ & $0.93(0.96)$ & $0.95(0.97)$ \\
\hline
\end{tabular}


subjective, different sets of parameters (threshold and run parameter) were tested; only a weak sensitivity was found in the estimated return level of the significant wave height based on ERA-Interim wave data.

The identified clusters are used to produce an event list for hindcast modelling with the described model chain. We assume that the same severe events would happen in a MFWAM simulation than in the ECWAM simulation of ERA-Interim (ECMWF, 2007) with the same wind. Both WAM models are indeed very similar, with only differences on the dissipation and on the assimilation. In consequence, the generation of the event list based on ERA-Interim wave reanalysis is a reasonable choice to avoid a complete reproduction of the 38 years with MFWAM. WWIII has not been driven directly by ERA-Interim wave spectra because of the large difference between the model resolutions $\left(1^{\circ}\right.$ for ERA-Interim, $0.5^{\circ}$ for MFWAM and $0.1^{\circ}$ for WWIII at the open boundary). Non-linear effects like wave-wave interaction or bottom-wave interaction are assumed to not affect wave heights in such a way that severe events would occur in the WWIII domain and not in the global model near the domain boundaries. Although the impact of currents on the wave height cannot be taken into account at the moment in the entire hindcast sample, their possible influence has been investigated in a sensitivity study (see below). The procedure for creating an event list was repeated for all ERA-Interim grid points along the boundary of the WWIII domain. One single list was then prepared on this basis, containing 249 events in the period from January 1979 until December 2016.

We compared the automatically prepared list with the positive hits of the official weather warnings issued by Météo France between 2006 and 2016, and found a good agreement (from 3932 included). The difference can be explained by the fact that the tide is not taken into account in the preparation of the event list, but it is part of the warning criteria. As the events were chosen based on the coarse ERA-Interim grid cells close to the open boundary of WWIII, it was tested, if it is necessary to prolongate the event period to allow the wave at the open boundary propagate to the coast by adding additional 6 hours, but found no necessity for doing this. The application of running windows of different sizes over randomly chosen grid points in the ERAInterim significant wave height data over the entire period showed that fitting a stationary GPD is reasonable.
Aarnes et al. (2015) discussed a jump in 1991 in ERA-Interim wave data. It corresponds to the introduction of altimeter data assimilation, and is also visible in the reanalysis in the order of $7 \mathrm{~cm}$ in the mean near French Guiana. As this effect is small, and since ERAInterim wave data are only used for the preparation of an event list, it is assumed not to affect the results. For the extreme value statistics, a homogeneous time series is necessary. To avoid to introduce inhomogeneities into the hindcast sample, data assimilation for MFWAM and WWIII is not applied in this study, as observations are not available over the entire 38 years. Hindcasts were prepared for the 249 events using the model chain, initialised from calm conditions. The spin-up lies in the order of eight days for MFWAM and three days for WWIII. For this reason, MFWAM was initialised eleven days before the beginning of the events, and WWIII three days in advance.

To investigate the influence of ocean currents on the significant wave height, hourly Mercator PSY4QV3R1 model surface current data has been retrieved for 2013 in $1 / 12^{\circ}$ resolution. The data were bilinearly interpolated onto a regular $0.5^{\circ}$ grid and included into the MFWAM forcing. To assess potential improvements in the model performance, the significant wave heights have been verified against altimeter data.

The spatial distribution of bias and scatter index are shown on Figure 2 and the scores for the AntillesGuyane region can be found in Table 2. Compared to the runs without surface currents, all the scores are improved statistically significant on the $95 \%$ level. In terms of the bias, the improvement is in the order of about a half centimetre. A major and significant improvement can be achieved by using ERA5 10 m winds.

The influence of the currents regarding improvements in the verification scores do not seem to be very strong. However, locally the current can have an effect between about -30 and $+40 \mathrm{~cm}$ on the significant wave height. This is shown on Figure 3 for a single time step. WWIII shows comparable features for the same time step (not shown). During the northerly swell season, current rings are present, the so-called NBC rings (mesoscale eddies) as well as associated currents (Baklouti et al., 2007; Fratantoni and Glickson, 2002). The presence of the NBC rings can explain the dipole structure in Figure 3. Ardhuin et al. (2017) discussed the influence of small scale currents on waves 

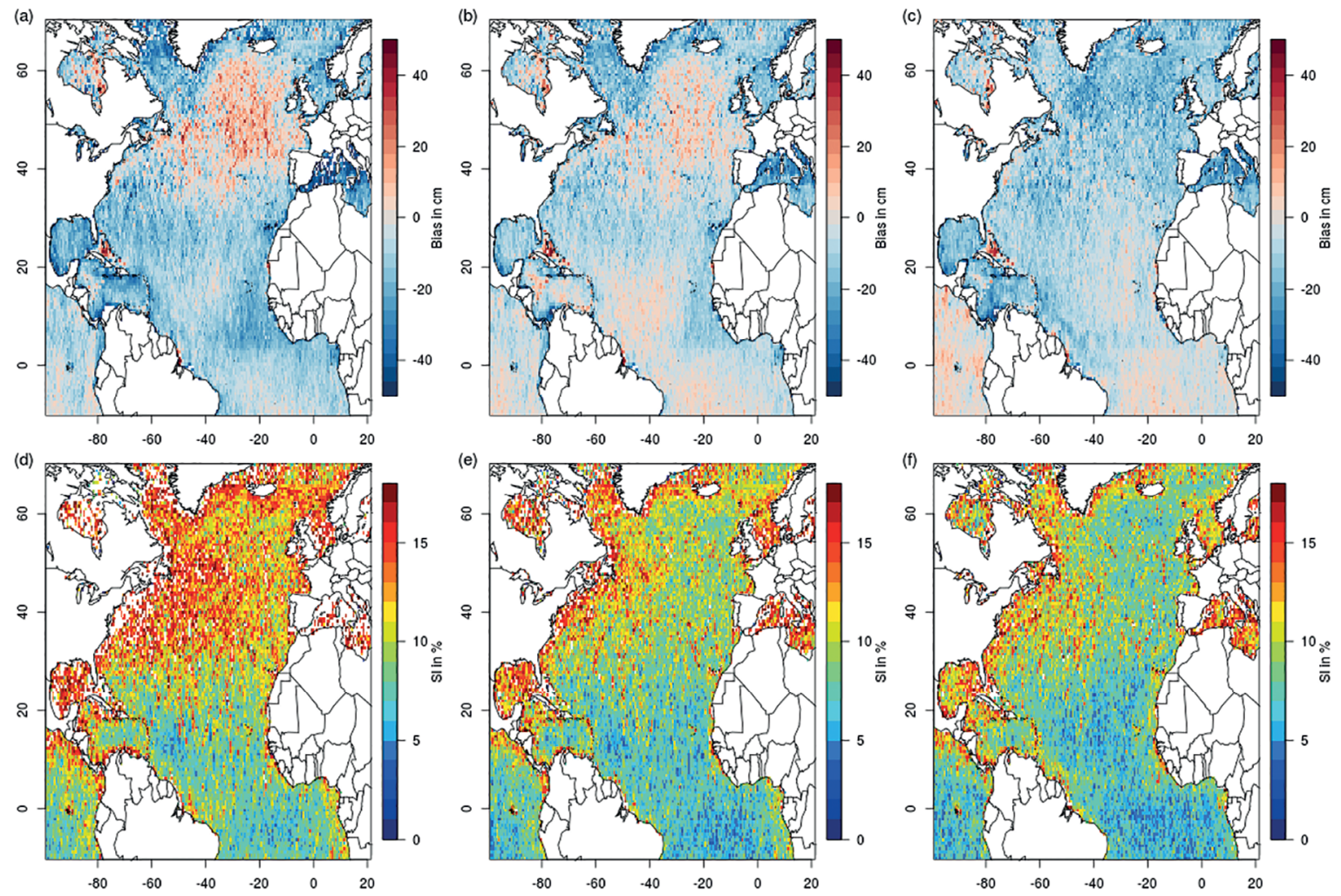

Figure 2. Bias (a-c) [cm] and scatter index (d-f) [\%] of MFWAM (a, b , d ,e) and ERA5 wave data (c, f) extracted from ECMWF Mars in $0.5^{\circ}$ verified against altimeter data for 2013. MFWAM was calibrated as in Fig. 1b,c,e,f, and driven by Mercator PSY4QV3R1 hourly surface currents from $1 / 12^{\circ}$ bilinear interpolated to $0.5^{\circ}$ and by either ERA-Interim (a,d) or ERA5 (b,e) $10 \mathrm{~m}$ winds.

Table 2. Verification scores of the significant wave height of 3 hourly data for 2013 for MFWAM $0.5^{\circ}$ with hourly surface currents from Mercator PSY4QV3R1 for the Antilles-Guyane region $75^{\circ} 00^{\prime} \mathrm{W}$ to $45^{\circ} 00^{\prime} \mathrm{W}$ and $5^{\circ} 00^{\prime} \mathrm{S}$ to $28^{\circ} 00^{\prime} \mathrm{N}$ (entire region of Fig. 2) against altimeter data.

\begin{tabular}{lccc}
\hline & $\begin{array}{c}\text { MFWAM calibrated with ERA- } \\
\text { Interim and hourly Mercator } \\
\text { current }\end{array}$ & $\begin{array}{c}\text { MFWAM calibrated with } \\
\text { ERA5 wind and hourly } \\
\text { Mercator current }\end{array}$ & $\begin{array}{c}\text { ECWAM from ERA5 extracted } \\
\text { from Mars interpolated on a } \\
0.5^{\circ} \text { grid }\end{array}$ \\
\hline Bias $[\mathrm{cm}]$ & $-13.9(-10.1)$ & $-4.7(-6.8)$ & $-10.8(-9.7)$ \\
rmse $[\mathrm{cm}]$ & $25.9(36.7)$ & $19.6(29.1)$ & $22.3(27.5)$ \\
Scatter index [\%] & $11.5(15.4)$ & $10.0(12.3)$ & $10.2(11.2)$ \\
Correlation & $0.94(0.96)$ & $0.95(0.97)$ & $0.95(0.98)$ \\
\hline
\end{tabular}

and showed similar structures for a different region. Figure 4 demonstrates the mean, minimum and maximum values of the differences over the entire year 2013. Unlike the mean and minima, the maxima are at the same positions as for the single event on Figure 3. As they have more or less comparable sizes, this suggests that the largest increases in the significant wave height are more or less at a constant position, whereas the NBC rings change their properties and position over time (Fratantoni and Glickson, 2002). Having only a few events during this short period, the maxima are probably mostly influenced by the strongest event. That is why a general statement is not possible and would require considering longer periods of time.

A test with monthly averaged currents over 2013 for 2013 was done. Table 3 shows an improvement of the verification scores compared to the simulation without currents (not significant for the bias, but significant for the other scores). Regarding the maxima of the current impact on the wave height over 2013, the dipole structures cannot be identified (not shown). This suggests that the scores are somewhat improved by the 


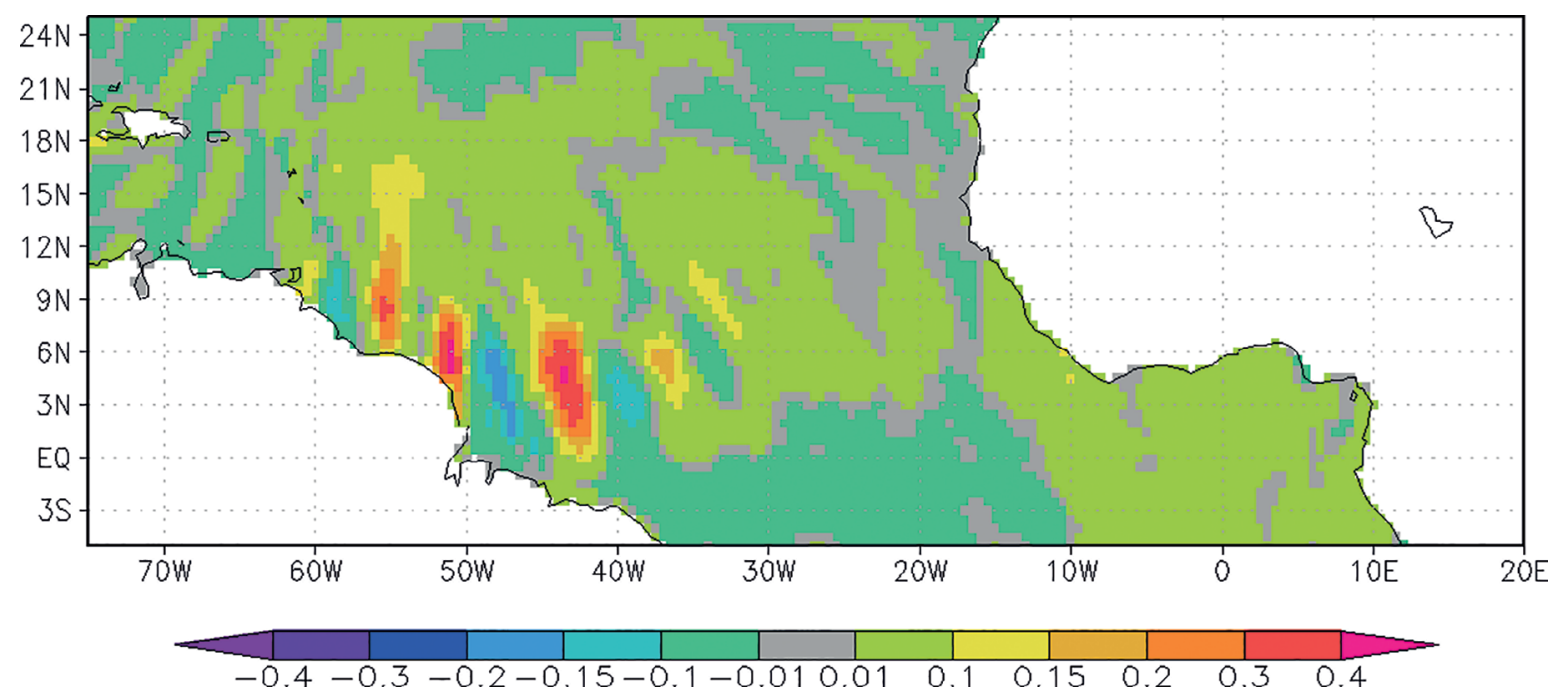

Figure 3. Difference $[\mathrm{m}]$ in significant wave height between calibrated MFWAM runs driven by ERA5 $10 \mathrm{~m}$ winds with and without Mercator PSY4QV3R1 surface current forcing for 15/01/2013 09:00h in the tropical North Atlantic.

Table 3. Verification scores of the significant wave height of 3 hourly data for 2013 for MFWAM $0.5^{\circ}$ with monthly averaged surface currents from Mercator PSY4QV3R1 over 2013 for the Antilles-Guyane region $75^{\circ} 00^{\prime} \mathrm{W}$ to $45^{\circ} 00^{\prime} \mathrm{W}$ and $5^{\circ} 00^{\prime} \mathrm{S}$ to $28^{\circ} 00^{\prime} \mathrm{N}$ (entire region of Fig. 2) against altimeter data.

\begin{tabular}{lc}
\hline & MFWAM calibrated with ERA5 wind and with monthly averaged Mercator current \\
\hline Bias $[\mathrm{cm}]$ & $-5.0(-7.3)$ \\
rmse $[\mathrm{cm}]$ & $20.2(29.4)$ \\
Scatter index [\%] & $10.2(12.4)$ \\
Correlation & $0.95(0.97)$ \\
\hline
\end{tabular}

mean current, but monthly averaging removes the daily variability in the Mercator model. Individual events do not seem to be well represented in the monthly averaged surface currents. Daily or sub-daily current data are necessary, but they are not available for the entire 38 years used in this study. That is why this effect cannot be taken into account yet for the estimation of return periods.

What is shown in Figures 3 and 4 is the result of the impact of the currents on the wave height. Mud banks can lead to a strong reduction of the wave height in the order of up to 70 per cent (Winterwerp et al., 2007). As these structures develop very fast compared to what is currently observable, and data are difficult to collect, it is not possible to take them into account. At the current stage, we started with sensitivity experiments using the implementation after Dalrymple and Liu (1978). Finally, the combined impact of currents and mud banks has to be taken into account, which is a long-term perspective.

The unstructured grid of the WWIII model for French Guiana contains 32,030 nodes (see the domain on Figure 5). A GPD is fitted for each node using maximum likelihood (Coles, 2001). The maxima of the 249 events at each individual grid point are taken. Again, the process of MRL plot and fit of a GPD for different thresholds was tested randomly at several grid points over the domain. At some grid points, it is necessary to use a higher threshold than the values of several of the weakest events in the list, for which reason the lowest hundred values per grid point were not used. One reason could be the negative average bias in the order of $-15 \mathrm{~cm}$ in MFWAM leading to a slight underestimation of the swell. By driving MFWAM with ERA5, this effect can be significantly reduced (Fig. 1c, Table 1). In WWIII the interaction with the bottom have probably an influence on the form of the significant wave height distribution at a grid point. It seems that near the coast, a larger number of events have to be removed from the sample to fulfil the requirements of the POT theory. The shape parameter of the GPD has a gradient perpendicular to the coast, with negative values close to zero at the shelf and reaching values of about 
(a)

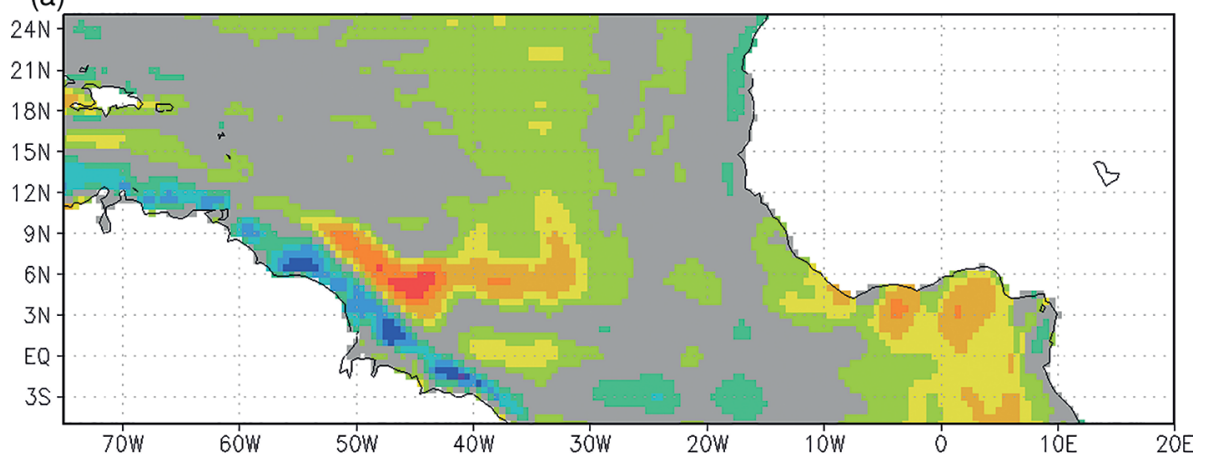

(b)

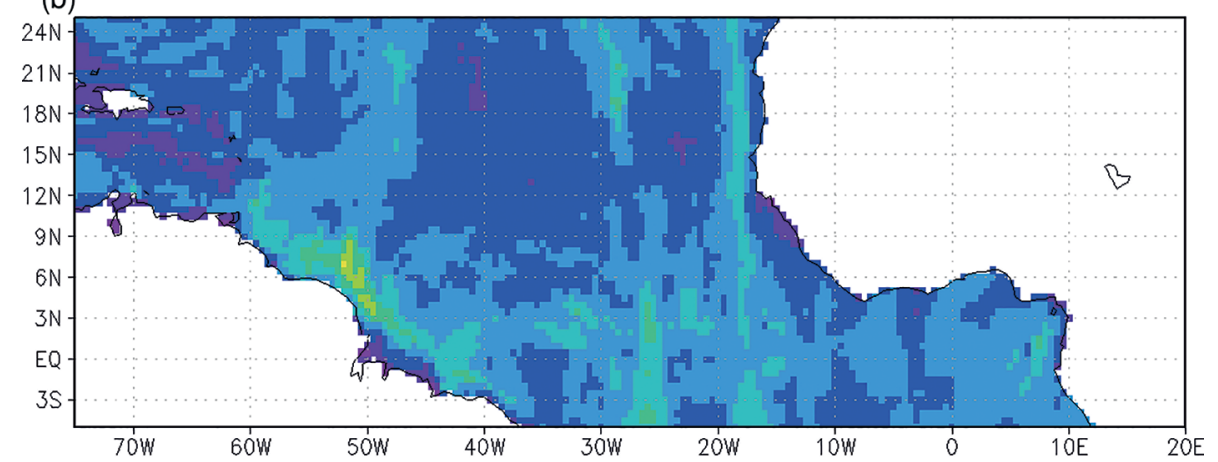

(c)
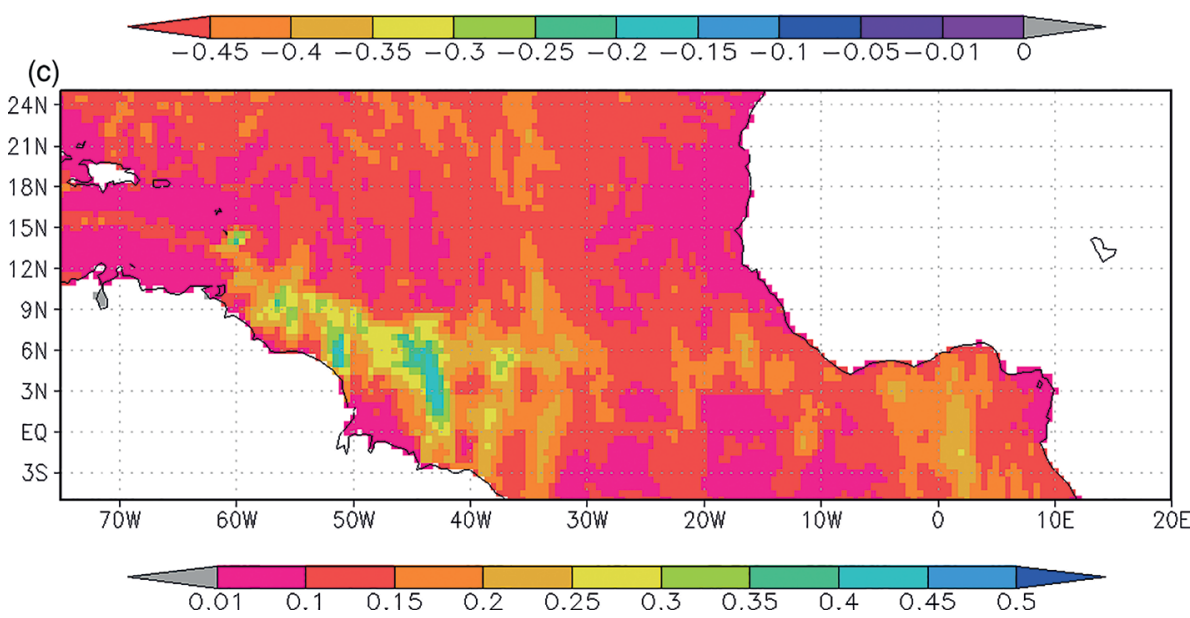

Figure 4. Difference [m] in significant wave height as in Figure 3 for entire 2013, mean (a), minimum value (b) and maximum value (c) at each individual grid point.

-1 at the coast between $53^{\circ} 15^{\prime} \mathrm{W}$ and $51^{\circ} 45^{\prime} \mathrm{W}$. In the western and eastern part of the coast, two small patches with a shape parameter close to 0 don't follow this general evolution. The profile-log-likelihood method (Coles, 2001) has been used to estimate confidence intervals at the $95 \%$ level. The estimated 100-year return levels, and associated lower and upper bounds of the $95 \%$ confidence intervals for the 32,030 nodes of the unstructured grid were interpolated onto a regular $0.0025^{\circ}$ grid using Akima (1978) for visualisation purposes (Figure 5).

Hosking and Wallis (1987) showed that the fit of a GPD for small sample sizes can be influenced by a bias in the fit parameters. To estimate the resulting bias in 100-year return levels, the jackknife method (leave-one-out with $n$ samples of size $n-1$, where $n$ is 
(a)

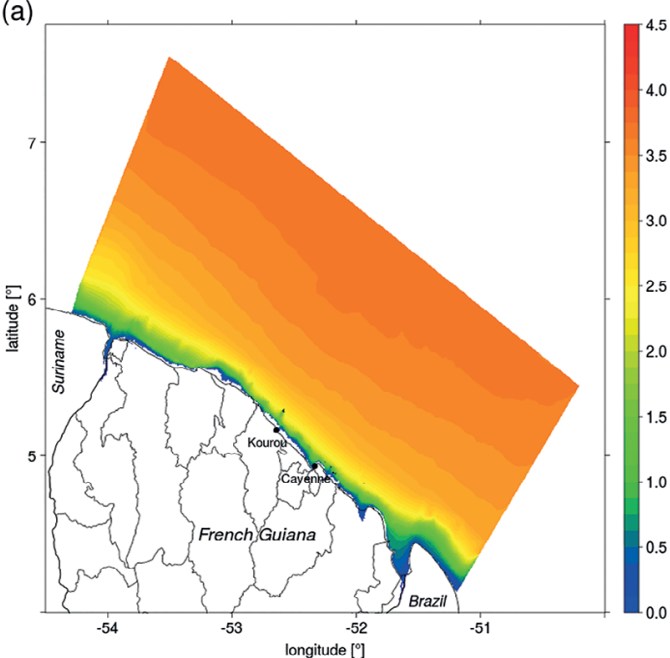

(b)

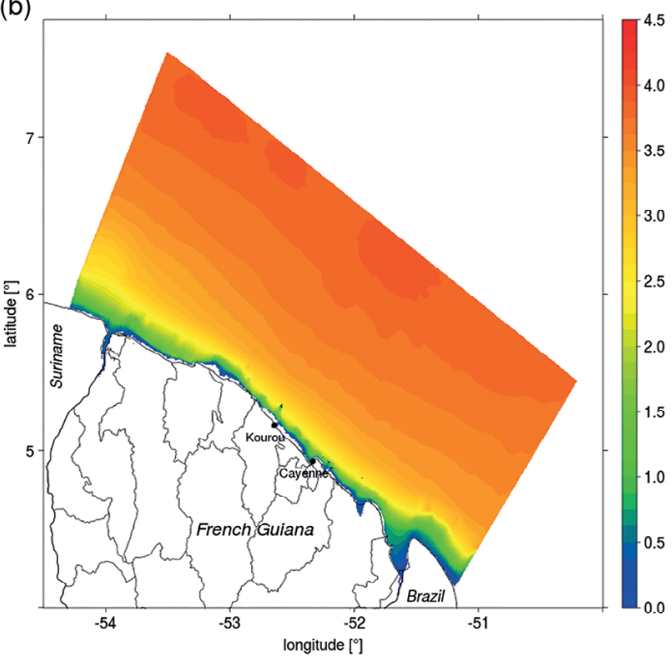

(c)

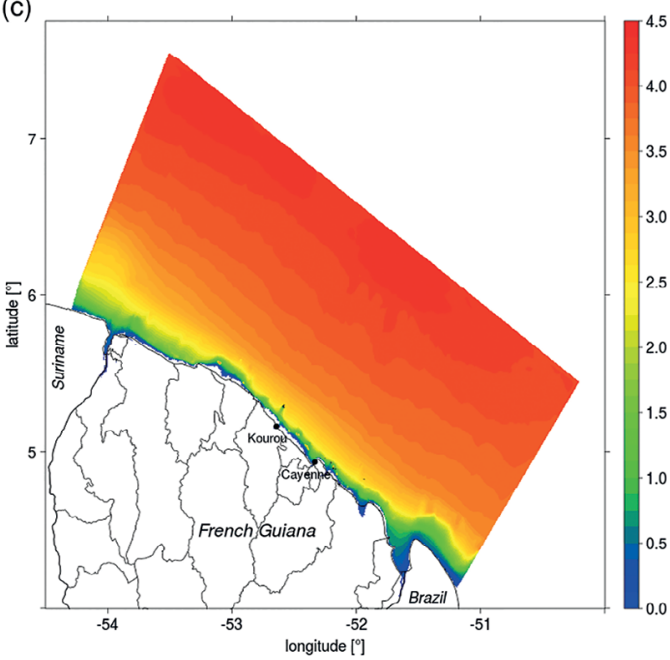

Figure 5. (b) Return level [m] of the significant wave height for a return period of 100 years. (a) Lower bound and (c) upper bound of the $95 \%$ confidence interval based on profile-log-likelihood considering 149 events. the number of events) method was applied (Efron and Tibshirani, 1986) and the result is shown on Figure 6a. Near the coast, which is the region of main interest for Météo-France, the bias is in the order of a few centimetres only. In regions with a medium water depth, the mainly negative bias can reach values of up to about minus 15 centimetres, whereas in deep water the bias is in the order of a few centimetres. These values have to be added with opposite sign to the estimation of the return level.

Future work may consider driving MFWAM $0.5^{\circ}$ with ERA5 wind data and nesting WWIII into this model as the results are tunable for the Antilles-Guyane region, unlike the ERA5 ECWAM wave data (ECMWF, 2016). For the entire region shown on Figure 1, the ECWAM wave data have better scores except for the bias than the calibrated MFWAM setup with currents. One may use the ERA5 wave spectra at the lateral boundaries of $0.1^{\circ}$ MFWAM from the operational chain, which covers a smaller domain, and drive the model with ERA5 wind data to benefit from higher spatial resolution of the model and the driving wind data. This would allow to include the effect of sea surface currents into MFWAM from which the wave spectra are used to drive WWIII. For coastal flooding, the combination of wave height and water level is relevant. Besides ocean/coastal currents and mud banks, the tide should also be taken into account in the wave model as well as in the statistics. Both, the significant wave height and the wave period should go in a next step into the estimation of the potential hazardousness of northerly swells for the French Guiana coast by applying a bivariate variant of the extreme value theory.

\section{ACKNOWLEDGEMENTS}

This study was financed by the Direction de l'Environnement, de l'Aménagement et du Logement (DEAL) of French Guiana. The setup of the WWIII model for French Guiana was created in cooperation between the SHOM and Météo France in the framework of the Homonim project with support from the DGPR and the DGSCGC. This study has been conducted using the CERSAT data base of Ifremer for the altimeter's measurements and E.U. Copernicus Marine Service Information and contains modified Copernicus Climate Change Service Information. We would like to thank Héloïse Michaud from the SHOM and Antoine Gardel 
(a)

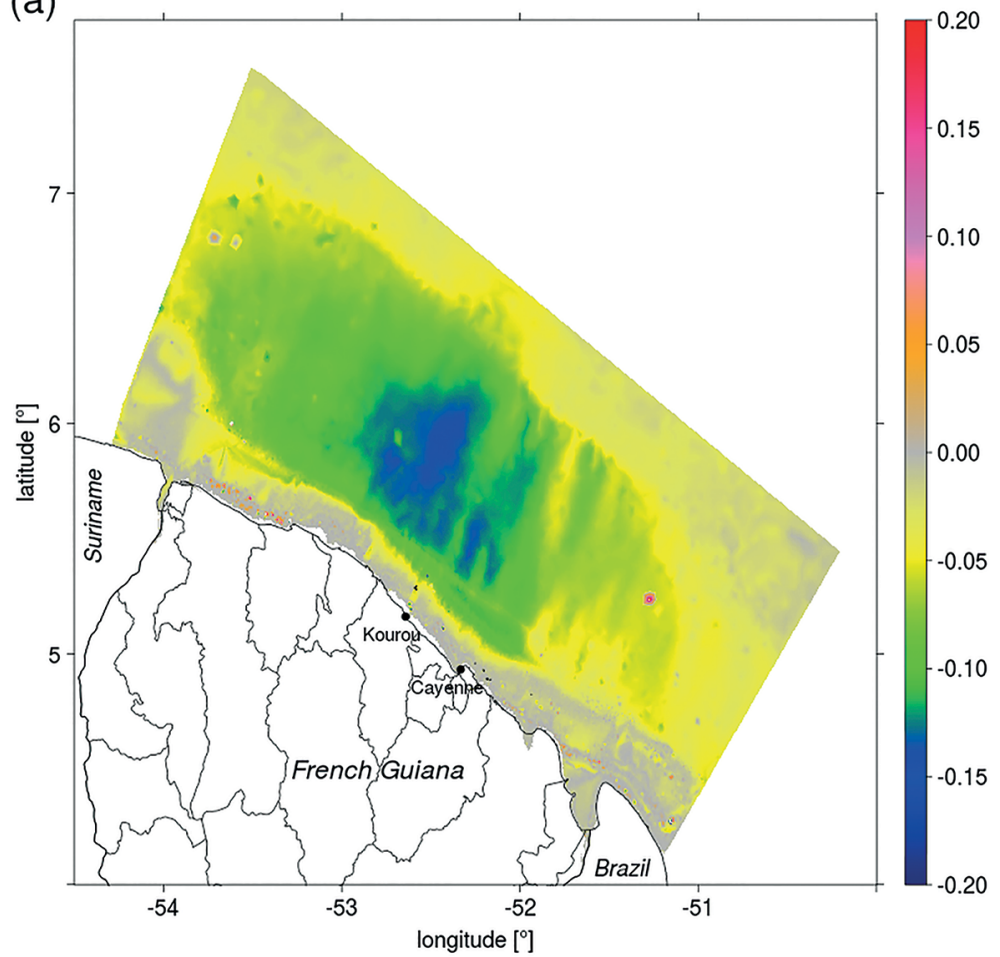

(b)

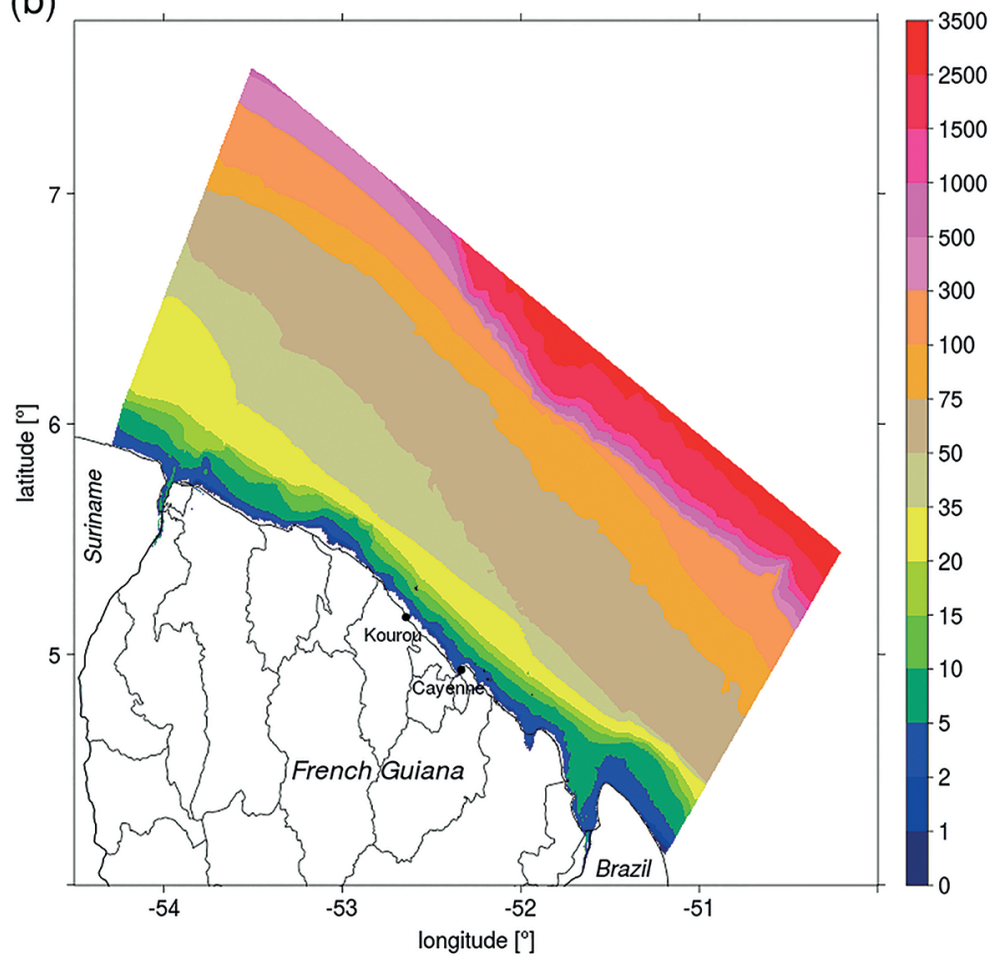

Figure 6. (a) Estimated bias [m] of the return level for a return period of 100 years based on the jackknife method. (b) Bathymetry [m]. 
from the CNRS for discussions concerning mud banks, Anne-Lise Beaulant and Marie Minvielle for a preparatory literature study, and Ali Bel Madani and Nicolas Morie for comments on the manuscript.

\section{REFERENCES}

AARNES, O. J., ABDALLA, S., BIDLOT, J. R. \& BREIVIK, Ø. 2015. Marine Wind and Wave Height Trends at Different ERAInterim Forecast Ranges. Journal of Climate, 28, 819-837.

AKIMA, H. 1978. A method of bivariate interpolation and smooth surface fitting for irregularly distributed data points. ACM Transactions Mathematical Software, 4, 148-159.

ARDHUIN, F., GILLE, S. T., MENEMENLIS, D., ROCHA, C. B., RASCLE, N., CHAPRON, B., GULA, J. \& MOLEMAKER, J. 2017. Small-scale open ocean currents have large effects on wind wave heights. Journal of Geophysical Research Oceans, 122, 4500-4517.

ARDHUIN, F., ROGERS, E., BABANIN, A. V., FILIPOT, J. F., MAGNE, R., ROLAND, A., VAN DER WESTHUYSEN, A., QUEFFEULOU, P., LEFEVRE, J. M., AOUF, L. \& COLLARD, F. 2010. Semiempirical Dissipation Source Functions for Ocean Waves. Part I: Definition, Calibration, and Validation. Journal of Physical Oceanography, 40, 1917-1941.

BAKLOUTI, M., DEVENON, J. L., BOURRET, A., FROIDEFOND, J. M., TERNON, J. F. \&

FUDA, J. L. 2007. New insights in the French Guiana continental shelf circulation and its relation to the North Brazil Current retroflection. Journal of Geophysical Research Oceans, 112, C2.

COLES, S. 2001. An Introduction to Statistical Modelling of Extreme Values, London, Springer-Verlag London.

DALRYMPLE, R. A. \& LIU, P. L. F. 1978. Waves over Soft Muds: A Two-Layer Fluid Model.

Journal of Physical Oceanography, 8, 1121-1131.

DEE, D. P., UPPALA, S. M., SIMMONS, A. J., BERRISFORD, P., POLI, P., KOBAYASHI, S., ANDRAE, U., BALMASEDA, M. A., BALSAMO, G., BAUER, P., BECHTOLD, P., BELJAARS, A. C. M., VAN DE BERG, L., BIDLOT, J., BORMANN, N., DELSOL, C., DRAGANI, R., FUENTES, M., GEER, A. J., HAIMBERGER, L., HEALY, S. B., HERSBACH, H., HÓLM, E. V., ISAKSEN, L., KÅLLBERG, P., KÖHLER, M., MATRICARDI, M., MCNALLY, A. P., MONGE-SANZ, B. M., MORCRETTE, J. J., PARK, B. K., PEUBEY, C., DE ROSNAY, P., TAVOLATO, C., THÉPAUT, J. N. \& VITART, F. 2011. The ERA-Interim reanalysis: configuration and performance of the data assimilation system. Quarterly Journal of the Royal Meteorological Society, 137, 553-597.

ECMWF (European Centre for Medium-Range Weather Forecasts). 2007. Part VII: ECMWF Wave Model IFS Documentation CY31R1 [cited 2018 Feb 16]. Available from: https:// www.ecmwf.int/en/elibrary/9224-part-vii-ecmwf-wavemodel

ECMWF (European Centre for Medium-Range Weather Forecasts). 2013. Part VII: ECMWF Wave Model IFS Documentation CY38R1 [cited 2018 Feb 16]. Available from: https:// www.ecmwf.int/sites/default/files/elibrary/2013/9248-partvii-ecmwf-wave-model.pdf
ECMWF (European Centre for Medium-Range Weather Forecasts). 2016. Part VII: ECMWF Wave Model IFS Documentation CY41R2 [cited 2018 Feb 16]. Available from: https:// www.ecmwf.int/en/elibrary/16651-part-vii-ecmwf-wavemodel

EFRON, B. \& TIBSHIRANI, R. 1986. Bootstrap Methods for Standard Errors, Confidence Intervals, and Other Measures of Statistical Accuracy. Statistical Science, 1, 54-75.

FAWCETT, L. \& WALSHAW, D. 2007. Improved estimation for temporally clustered extremes. Environmetrics, 18, 173-188.

FRATANTONI, D. M. \& GLICKSON, D. A. 2002. North Brazil Current Ring Generation and Evolution Observed with SeaWiFS. Journal of Physical Oceanography, 32, 1058-1074.

GORMAN, R. M. \& OLIVER, H. J. 2018. Automated model optimisation using the Cylc workflow engine (Cyclops v1.0). Geoscientific Model Development, 11, 2153-2173.

GRATIOT, N., GARDEL, A. \& ANTHONY, E. J. 2007. Tradewind waves and mud dynamics on the French Guiana coast, South America: Input from ERA-40 wave data and field investigations. Marine Geology, 236, 15-26.

HOSKING, J. R. M. \& WALLIS, J. R. 1987. Parameter and Quantile Estimation for the Generalized Pareto Distribution. Technometrics, 29, 339-349.

MICHAUD H.; MORIO O.; GENSAC E.; OSINSKI R.; DALPHINET A.; CASITAS, S. \&

PASQUET, A. 2018. Mud and sand effects on wave propagation over the French Guiana coasts, Proceedings of XVeme Journées Nationales Génie Côtier-Génie Civil, La Rochelle, France, 2018 May 29-31.

QUEFFEULOU, P. 2004. Long-Term Validation of Wave Height Measurements from Altimeters. Marine Geodesy, 27, 495510.

TOLMAN, H. L. 1991. A Third-Generation Model for Wind Waves on Slowly Varying, Unsteady, and Inhomogeneous Depths and Currents. Journal of Physical Oceanography, 21, 782-797.

THE WAMDI GROUP. 1988. The WAM Model - A Third Generation Ocean Wave Prediction Model. Journal of Physical Oceanography, 18, 1775-1810.

TOLMAN, H. L. \& the WAVEWATCH III ${ }^{\circledR}$ Development Group 2014. User manual and system documentation of WAVEWATCH III ${ }^{\circledR}$ version 4.18 [cited 2018 Feb 16]. Available from: http://polar.ncep.noaa.gov/waves/wavewatch/manual. v4.18.pdf

VAN LEDDEN, M., VAUGHN, G., LANSEN, J., WIERSMA, F. \& AMSTERDAM, M. 2009.

Extreme wave event along the Guyana coastline in October 2005. Continental Shelf Research, 29, 1, 352-361.

WINTERWERP, J. C., DE GRAAFF, R. F., GROENEWEG, J. \& LUIJENDIJK, A. P. 2007. Modelling of wave damping at Guyana mud coast. Coastal Engineering, 54, 249-261.

ZAMBRESKY, L. 1989. A verification study of the global WAM model December 1987 - November 1988. Technical Report No. 63 [cited 2018 Feb 16]. Available from: https://www.ecmwf.int/sites/default/files/elibrary/1989/13201-verificationstudy-global-wam-model-december-1987-november-1988. pdf 